\title{
Sixty years of dislocations
}

\section{PLACID RODRIGUEZ}

Indira Gandhi Centre for Atomic Research, Kalpakkam 603 102, India

\begin{abstract}
It is well-known that with the appearance of three independent papers by Taylor, Polanyi and Orowan in the year 1934, the concept of crystal dislocations was born. Since then, dislocation theory has had many spectacular successes. It is quite appropriate therefore to be aware of the state of development of this exciting subject, sixty years after its discovery.

A flavour for the vast subject of the applications of dislocation mechanisms to real materials is presented by choosing three examples, one each, drawn from metallurgy. physics and electronics. The topic of 'Strength of metals and alloys' is the first one, as this is also the author's area of research. The phenomenon of solidification and crystal growth forms the next topic, especially in view of the seminal contributions made by A R Verma and his school from India. Dislocations play a useful role in the strengthening of solids, but how influential are they in affecting the performance of modern semiconductor devices? In the third example, the interesting and painstaking work done to settle this question is reviewed

Can we regard carbon fibre as the transistor of dislocation theory? How shall we understand the long-established effects such as corrosion-fatigue, superplasticity and shape memory as well as the electrochemical and electro-mechanical properties of dislocations in semiconductor and non-metallic crystals? Answers to these questions belong to the realms of the future developments in dislocations. The talk is concluded with a discussion of these topics.
\end{abstract}

Keywords. Dislocations; polycrystal work hardening; crystal growth.

\section{Introduction}

I feel honoured to be invited to deliver the Platinum Jubilee Lecture in the Material Sciences Section and I would at the outset like to thank the Indian Science Congress Association, its General President Dr S C Pakrashi and the President of the Material Sciences Section of this year, my colleague and friend Dr Baldev Raj.

The title of the talk evidently conveys what I intend to say; it is to recount the fascinating story of the evolution over the past 60 years, of the science of dislocations. The introduction in the year 1934 of the concept of crystal dislocations to explain the low shear strength, the high plasticity and allied phenomena like work hardening of metals was an important milestone in the evolution of the subject of strength of solids.

The plan of the talk is as follows. The scientific studies carried out before the advent of the concept of dislocations in 1934 (Orowan 1934; Polanyi 1934; Taylor 1934) is briefly recounted. The situation after the introduction of the dislocations is next described drawing material mainly from the subject of strength of materials. In what follows, the impact made by the introduction of the dislocation concept in the field of crystal growth is taken up for discussion. Reducing or, if possible, totally etiminating dislocations, is one of the major challenges posed by the semiconductor technology. Some of the results available on the influence of dislocations on the performance of semiconductor devices such as a laser, a light emitting diode, and a field effect transistor are summarized. 
Table 1. Some early concepts and developments related to the strength of materials.

\begin{tabular}{|c|c|c|}
\hline ca 1500 & : da Vinci & : Breaking load of iron wires \\
\hline 1638 & : Galileo & : Bending of beams \\
\hline 1678 & : Hooke & : Hook's law \\
\hline 1773 & : Colomb & : Shear stress and shear strain \\
\hline 1807 & : Young & : Elastic modulus \\
\hline 1830 & : Poisson & : Poisson's tatio \\
\hline 1833 & : Navier & : Shear modulus \\
\hline 1837 & : St. Venanat & : 'Glissement' (Glide) \\
\hline 1867 & : Reusch & : Slip and twinning in rock salt and calcite \\
\hline 1883 & : O. Mugge & : Slip bands in metals \\
\hline 1899 & : O. Mugge & : Twinning in metals \\
\hline 1912 & : Von Laue, Braggs & : X-ray diffraction \\
\hline 1913 & $\begin{array}{l}\text { Critical cold work method for } \\
\text { growing single crystals }\end{array}$ & \\
\hline 1914 & : W L Bragg & : The crystalline nature of metals \\
\hline 1917 & $\begin{array}{l}\text { : Czochralski method for growing } \\
\text { crystals }\end{array}$ & \\
\hline 1923 & : Zone melting & \\
\hline 1924 & : Schmid & : Critical resolved shear stress \\
\hline 1926 & : Frenkel & : Theoretical shear strength \\
\hline 1935 & : E Schmid and W Boas & : The book "Kristallplastizitat" \\
\hline 1935 & : C F Elam & : The book "Distortion of Metal Crystals" \\
\hline
\end{tabular}

Note: See references 3, 11, 12, 14 and 15 quoted in Rodriguez (1994) for more details and original references.

As the topic chosen for this talk has a vast literature, an attempt to cite all original papers and reviews will end up in a bibliography running to several hundred references. The monumental works edited by Nabarro (1979-1989), entitled 'Dislocations in Solids', which has reached the 8th volume, is the modern sourcebook on dislocations. However, more than a hundred references relevant to the first five sections of this article may be found in my earlier paper (Rodriguez 1994). Hence, in this article, only a few relevant papers are listed under References.

\section{Before dislocations}

A survey of the history of science shows that among the then existing concepts, the following were relevant to the discovery of crystal dislocations in 1934 (table 1): strength, shear stress, crystalline nature of solids, critical resolved shear strength and theoretical shear strength. Leonardo da Vinci appears to be the first to have concerned himself with the strength of materials $c a 1500$ by carrying out experiments to determine the breaking load of metal wires. The famous 'Galileo's Problem' of bending of beams is reckoned today as the starting point of the science of elasticity or applied mechanics or 'strength of materials' as it is often referred to. It took another forty years before the basic law of elasticity was enunciated by Robert Hooke (1678). It was only more than a century after Hooke that the importance of his law was realized with Young establishing in 1807 that the constant in Hooke's law is a material property and thereby inventing the concept of elastic modulus. Other concepts like shear stress, shear strain, Poisson's ratio and shear modulus soon followed. 
Table 2. Examples of phenomena and concepts related to plastic deformation and strengthening mechanisms known before the theory of crystal dislocations.

\begin{tabular}{|c|c|c|}
\hline 1775 & : Grignon & : Properties of steel better with fine grains \\
\hline 1824 & : G H Dufour & $\begin{array}{l}\text { Breaking load of annealed wire is half that of unannealed wire; } \\
\text { the wire thins down at the point of rupture }\end{array}$ \\
\hline 1827 & : Lagerhjeh & : Work hardening, first hydraulic testing machine \\
\hline 1830 & : Vicat & : Phenomenon of creep, tests on wires for 33 months \\
\hline 1837 & : A F W Brix & : Yield point in steel wires \\
\hline 1866 & : Bauschinger & : The Bauschinger effect \\
\hline 1868 & : Muschet & : Tungsten steels for cutting applications \\
\hline 1884 & : Hadfield & : $12 \%$ Mh steel \\
\hline 1896 & : Robert Austen & : Phase diagram of $\mathrm{Fe}-\mathrm{C}$ system \\
\hline 1898 & : Taylor and White & : Heat treatment of high tungsten steels \\
\hline 1903 & : Heycock and Neville & : Phase diagram of $\mathrm{Cu}-\mathrm{Sn}$ system \\
\hline 1906 & : Wilms & : Age hardening of aluminium alloys \\
\hline \multicolumn{3}{|r|}{ 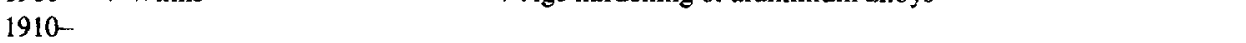 } \\
\hline 1914 & : Andrade & : Creep laws \\
\hline 1912 & : Brearly and Maurer & : Stainless Steels \\
\hline 1916 & : D K Bullens & : The book "Steel and its heat treatment" \\
\hline 1919 & : Merica et al & : Al-Cu phase diagram \\
\hline 1923 & : Portevin and Le Chatlier & : P L effect (Repeated yielding) \\
\hline 1925 & : W J Berry & : Finishing rolling/forging of steel to lower temperatures leads to \\
\hline 1928 & : H. Hcnemann and F Luke & fine ferrite grain size and higher strength. \\
\hline 1926 & : R W Bailey & : Recovery theory of creep \\
\hline 1929 & : Bedford and Pilling & : First superalloy by the addition of $\mathrm{Ti}$ and $\mathrm{Al}$ to $80 / 20$ Nichrome \\
\hline 1929 & : Merica & \\
\hline 1929 & : Norton & $\begin{array}{l}\text { Power law creep (The book: Creep of steel at higher } \\
\text { temperatures). }\end{array}$ \\
\hline
\end{tabular}

Note: See references 3,11,12,14, 15 and 35 in Rodriguez (1994) for more details and original references.

Parallel to the advances in the theory of elasticity were the developments in the area of mechanical testing. The first testing device was developed in the middle of the eighteenth century and most of the later work was done mainly by civil engineers who were concerned with the strength of the structures which they were to build.

At this stage, it is interesting to survey the progress in the metallurgical knowledge that took place during the same period up to 1934. Examples of phenomena and concepts related to plastic deformation and strengthening mechanisms known before the theory of crystal dislocations are chronologically listed in table 2 . By the mid-19th century, it was known that mechanical properties like yield strength and ductility of metals could be altered through variations in chemical composition and heat treatment. The Bauschinger effect was discovered in 1866. The development of many alloy steels also took place around the same time. Hadfield steel, which is still used in railway applications, was invented in as early as 1884 . Precipitation hardening in aluminium alloys was discovered in 1906 and was understood with the help of phase diagrams, which were still investigated by the experimental techniques of optical metallography and thermal analysis only. While yield point in steel was discovered in 1837 by Brix, the phenomenon of repeated yielding in aluminium alloys was reported by Portevin and Le Chatlier in 1923. We find in table 2 that stainless steels were developed in 1912 followed by the first superalloy in 1929 by the addition of Ti and Al to 80/20 Nichrome. We also find that many aspects of creep were also known by this period. 
At this stage I must point out to a great discovery that took place in 1912 , which was also crucial to the subsequent developments in our understanding of plastic deformation. The discovery of X-ray diffraction in 1912 by Von Laue and his associates in Germany and by the Braggs in England indeed was an important turning point not only for the future course of physical metallurgy but for the whole branch of solid state science. The developments in crystallography, till then had been mostly due to the efforts of mineralogists. The phenomena of glide (slip) and twinning were first discovered in 1867 in rocksalt and calcite. Slip bands in metals were observed in as early as 1883 by O Mugge of Gottingen. In 1899 he also reported twinning in $\alpha-\mathrm{Fe}, \mathrm{As}, \mathrm{Sb}$ and $\mathrm{Bi}$ and glide in $\mathrm{Cu}, \mathrm{Ag}$ and $\mathrm{Au}$. With the availability of metal single crystals, the period between the years 1912 and 1934, saw extensive studies on the plastic properties of metal crystals notably by Andrade, Carpenter. Elam, Taylor, Polanyi, Schmid and Boas. In 1922 Mark, Polanyi and Schmid proposed the 'disc model' for glide. In 1924 Schmid formulated the critical resolved shear stress law which led to the description of the stress--strain curve using the shear stress in the slip system and the amount of slip. The extensive studies on crystal plasticity during this period have been compiled and summarized in the two classical books 'Kristallplastizitat' by Schmid and Boas and 'Distortion of Metal Crystal' by Elam both published in 1936.

Towards the end of this period, it had become obvious that the simple geometric model of slip was unsatisfactory for many reasons. The critical resolved shear strength of metals experimentally determined were two or three orders of magnitude lower than the shear strength theoretically calculated, based on the glide model. The phenomenon of work hardening also could not be rationalized by the slip model; nor could the dependence of yield strength and work hardening on temperature and strain rate. Further, X-ray diffraction studies had shown that after deformation, the crystal structure was not as perfect as before. It was realized that the low strength of crystals is due to the presence of defects and these defects increased in density with plastic deformation. In 1934 Taylor, Polanyi and Orowan independently proposed dislocations as the defects responsible for the plastic properties of crystals.

\section{After dislocations}

The preceding discussion and table 2 have brought to focus the advances made with respect to strengthening methods and deformation phenomena without realizing the role of dislocations. The period between 1934 and 1964 saw the extensive application of dislocation theory to explain the various experimental observations (table 3 ). In the early years of this period a number of developments in the theory of crystal dislocations took place. Orowan who by then had gone over from Berlin to Birmingham interacted with the Physicist Rudolph Peierls leading to the evaluation of the Peierls-Nabarro stress (Peierls 1940; Nabarro 1947). The now famous Orowan equation for the strain rate,

$$
\dot{\varepsilon}=\rho_{\mathrm{m}} b \bar{V},
$$

( $\rho_{\mathrm{m}}$ the dislocation density, $b$ the Burgers Vector and $\bar{V}$, the average velocity of dislocations) was formulated by him in 1940. The Orowan mechanism of precipitation hardening by which dislocations bow around precipitates leaving loops around the latter was presented at an Institute of Metals Symposium in 1947 (Orowan 1947). 
Table 3. Important milestones between 1934 and 1964 in our understanding of the strength of metals and alloys.

\begin{tabular}{|c|c|c|}
\hline 1934 & : Taylor, Polanyi and Orowan & Crystal dislocations \\
\hline 1939 & : J M Burgers & Curved and screw dislocations \\
\hline 1940 & : Orowan & Orowan equation, $\varepsilon_{\mathrm{p}}=\rho_{\mathrm{m}} b V$ \\
\hline 1940 & : R Peierls & : (Nabarro 1947) Peierls-Nabarro Stress \\
\hline 1941 & : J S Koehler & : (Peach and Koehler 1950) Force on a dislocation \\
\hline 1947 & : R W Cahn & : Discovery of polygonisation \\
\hline 1947 & $\begin{array}{l}\text { Symposium on Internal Stresses in } \\
\text { Metals and Alloys (London, Institute } \\
\text { of Metals) }\end{array}$ & \\
\hline 1947 & $\begin{array}{l}\text { Bristol Conference on Strength of } \\
\text { Solids (London: Phys. Soc.) }\end{array}$ & \\
\hline 1947 & : Shockley & : Partial dislocations and dislocation reactions \\
\hline 1947 & : Bragg and Nye & $\begin{array}{l}\text { Bubble raft model (1950: Bilby's three dimensional } \\
\text { model of dislocations) }\end{array}$ \\
\hline 1949 & : Shockley and Read & : Dislocation model of small angle boundaries \\
\hline 1950 & : Frank and Read & : Frank-Read sources of dislocation multiplication \\
\hline 1950 & $\begin{array}{l}\text { Pittsburgh symposium on plastic de- } \\
\text { formation }\end{array}$ & \\
\hline 1951 & : 9th Solway Conference. Brussels & \\
\hline 1952 & : Herring and Galt & : Whiskers of tin \\
\hline 1952 & : Nabarro & : Advances in Physics \\
\hline 1953 & : Books by Cottrell and Read & \\
\hline 1956 & : Burgers Brothers & $\begin{array}{l}\text { Relationship between partial dislocations and stack- } \\
\text { ing fault }\end{array}$ \\
\hline 1956 & : Hirsch and Horne & : TEM observation of dislocations \\
\hline 1956 & : Bollmann & : Al Whelan in stainless steel \\
\hline 1956 & : Amelinck $x$ & : Etch pit studies \\
\hline 1956 & : Johnston and Gilman & : Etch pit studies in LiF \\
\hline 1957 & : J C Fisher et al (eds) & $\begin{array}{l}\text { Dislocations and mechanical properties of crystals, } \\
\text { (New York:Wiley) }\end{array}$ \\
\hline 1959 & : Johnston and Gilman & : Yield points and dislocation multiplication in $\mathrm{LiF}$ \\
\hline 1960 & : Meakin and Wilsdorf & : Measurement of dislocation densities in brass \\
\hline 1961 & : A S Keh & : Measurement of dislocation densities in Fe by TEM \\
\hline 1963 & : Thomas and Wasburn (eds) & : Electron microscopy and strength of crystals \\
\hline
\end{tabular}

Another significant development in the pre-world war II period was the introduction of the curved and screw dislocations by J M Burgers (1939), which completed the theoretical picture of the geometry of the dislocations. The next important developments were the concepts of dislocation reactions and of partial dislocations. The possibility of a phase transformation between the two close packed lattices FCC and $\mathrm{HCP}$ by the movement of a Shockley partial was suggested by the Burgers brothers and demonstrated by W G Burgers (1956). Also noteworthy was the dislocation model of small angle boundaries developed by Shockley and Read (1949) and the model of Frank-Read sources (Frank and Read 1950) for dislocation multiplication.

The developments in the application of dislocation theory to plastic deformation in the post-world war II period were a mixed story of both success and scepticism. The scepticism arose because "it became a fashion to invent a dislocation theory of almost every experimental result in plastic deformation.... it became apparent that dislocations could explain not only any actual result but virtually any conceivable result usually in several different ways". The removal of this scepticism and the acceptance of the role of 
dislocations in plastic deformation was achieved by systematic efforts of consolidation and critical appraisal, which involved step-by-step development of basic theory from first principles, and a search for clear-cut experiments to check the theory. The results of these efforts have been summarized in the classic books on dislocations by Cottrell (1953), Read (1953) and Friedel(1956), in a number of conference proceedings and in the numerous text books and treaties on the mechanical behaviour of materials. The books by Van Bueren (1960), Nabarro (1967) and Hirth and Lothe (1968) also should be mentioned in this context.

The first experimental evidence for the existence of dislocations was the discovery of polygonization (formation of subgrains or tilt boundaries on annealing in cold worked crystals) by Cahn (1949). Another successful discovery predicted by dislocation theory was the high strength of whiskers or perfect crystals. Following the observation of Herring and Galt (1952) that thin tin crystals $\sim 1 \mathrm{~mm}$ diameter could sustain elastic strains of up to $2 \%$ without any plastic deformation, and had fracture strengths approaching the theoretical strength of perfect crystals, whiskers with strengths approaching the theoretical strengths have been grown of many metallic and nonmetallic materials. The Frank-Read source as a mechanism of multiplication for dislocation proposed in 1950 was observed by Dash (1956) in silicon. Etch pits as a method of revealing dislocations emerging at a surface was clearly established by the experiments of Gilman and Johnston (1959) on LiF, which showed that the density, motion and velocity of dislocations under stress could be studied through etch-pit techniques and agreed with theoretical predictions. The culminating evidence was the 'direct' observation of dislocations by transmission electron microscopy of thin films in aluminium by Hirsch et al (1956) and in stainless steel by Bollmann (1956). On the theoretical side, a major development was the application of dynamic theory of diffraction contrast by Howie and Whelan in 1961, which facilitated the interpretation of electron micrographs of dislocations and other defects. The successful integration of theory and experiment, which led to the development of mechanical metallurgy as a mature subject is illustrated by the numerous textbooks on the subject that were published during the sixties.

\section{Dislocations and strengthening mechanisms}

The understanding of strengthening mechanisms has been a major concern from the beginning and between 1960 to 1975 there were at least eleven symposia focussing attention on this aspect (table 4). A brief discussion of the important developments in the understanding of strengthening mechanisms is given below.

As early as 1947, the Orowan mechanism of dislocations looping around second phase particle was suggested. The second possibility of dislocations cutting through the precipitates was also realized early enough. The Orowan stress is inversely proportional to the interparticle spacing, whereas the stress to cut through a precipitate increases with the size of the particle. Generally, therefore, for the same volume fraction of the second phase, the yield strength is determined by the cutting mechanism at small precipitate sizes, whereas the Orowan mechanism takes over at large sizes (figure 1). Figure 2 is a TEM picture of deformation in Nimonic alloy PE16 illustrating that in actual microstructures, which have a range of sizes for the second phase, both types of interactions do take place (Bhanu Sankara Rao et al 1983). 
Table 4. Symposia held between 1960 and 1975 on topics related to strengthening mechanisms.

1960 : ASM Conference (Proceedings published in 1962)

1963 : The Relation between the Structure and Mechanical Properties of Metals (NPL Symp.) HMSO, London

1964 : The strengthening of Metals D Peckner (ed) Reinhold, New York

1966 : Strengthening Mechanisms in Metals and Ceramics (Syracuse University Press)

1966 : Oxide Dispersion Strengthening (Met. Soc. Conf., Gordon and Breach, New York)

1968 : Work Hardening, J P Hirth and J Weertman (eds) Gordon and Breach, New York

1968 : Work hardening in Tension and Fatigue A W Thompson (ed) Met. Soc. Conf.

1969 : Zurich Symposium on Steel Strengthening Mechanisms (Climax Molybdenum, 1970)

1969 : Quantitative Relation between Properties and Micro-structure, D G Brandon and A Rosen (eds) Israel University Press, Jerusalem

1972 : Strengthening Methods in Crystals A Kelly and R B Nicholson (eds) Applied Science Publishers, London

1975 : Physics of Solid Solution Strengthening E W Collings and H L Gegel (eds) Plenum Press, New York.

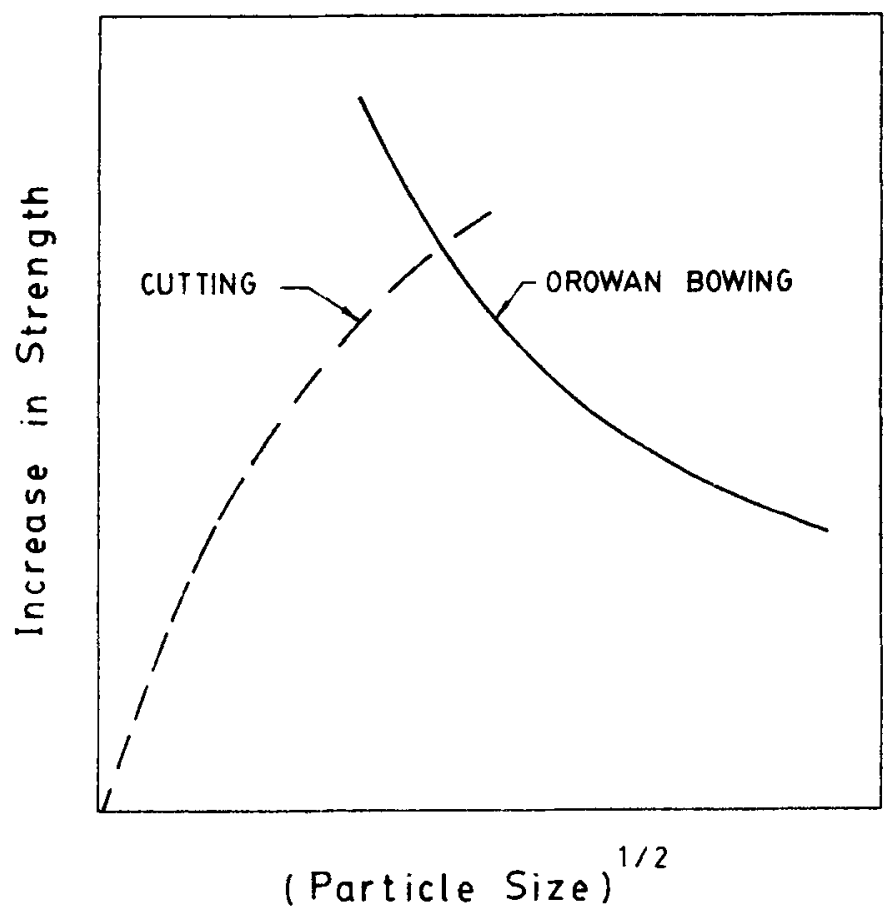

Figure 1. Influence of particle size on deformation mechanism in alloys strengthened by the second phase.

The third possibility applies to a situation when the second phase is non-deformable and the Orowan stress is higher than the stress required to cause fracture of the second phase or decohesion at the interface. In such a situation, the physical model developed by Ansell and Lenel (1960) will apply; yielding occurs when the shear stress due to dislocations piled up at the interface, plastically deforms, fractures or causes 

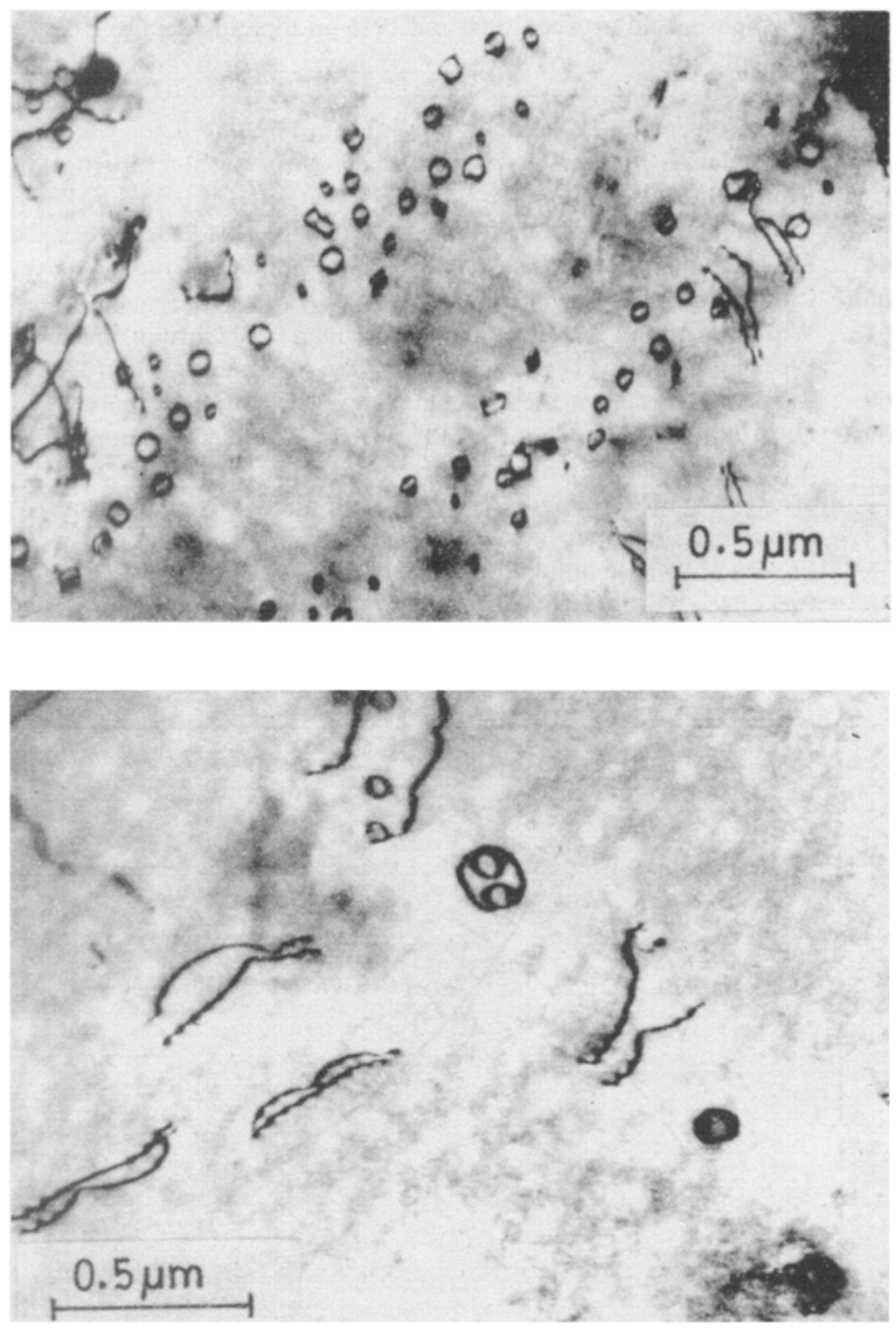

Figure 2. TEM micrographs of nimonic PE 16 superalloy aged at $973 \mathrm{~K}$ for $1000 \mathrm{~h}$ followed by tensile deformation up to $3 \%$ plastic strain. Both dislocation loops created by Orowan bowing and dislocation pairs indicative of particle shearing of gamma-prime precipitates are seen (Bhanu Sankara Rao et al 1983).

decohesion of the dispersed second phase. The first experimental proof for the AnsellLenel mechanism was provided by a systematic study by Rodriguez and Asundi (1970) of the room temperature mechanical properties of eutectoidal binary aluminium bronze $(\mathrm{Cu}+11.8 \mathrm{wt} \% \mathrm{Al})$ as a function of interlamellar spacing in the pearlite. Specimens with different interlamellar spacing were produced by isothermal transformations at various sub-critical temperatures. The proportional limit, the $0.2 \%$ yield strength and the fracture strength were found to be inversely related to the square root of the lamellar spacing as predicted by the Ansell-Lenel mechanism. Additional evidence for the mechanism was provided from metallographic studies which showed the appearance of cracks in the hard second phase, even at plastic strains as small as $0.1 \%$. 
As far as solid solution strengthening is concerned, direct effects due to atomic size mismatch and modulus difference as well as indirect effects through lowering of stacking fault energy and ordering are now well understood. Fleischer's (1961) theory, in which the modulus effect and size misfit were incorporated into a single equation that predicts a $\mathrm{C}^{1 / 2}$ dependence for the strength increase with the atomic concentration, $\mathrm{C}$ of the solute, was the most celebrated and widely quoted in the sixties and seventies. In Fleischer's theory, following Friedel, an average distance between individual solute atoms is used. In the 'Statistical' theories, that came into the fore in the seventies, the statistics of forces acting on the elements of a dislocation in a field of obstacles which are randomly spaced, is taken into account using statistical averaging and Green's function methods. When the obstacles are groups of solute atoms similar to the model originally proposed by Mott and Nabarro (1948), the strength is governed by $C^{2 / 3}$ law. It is generally believed that dilute solid solutions obey a Friedel limit (yield stress varies as $\mathrm{C}^{1 / 2}$ ), whereas in more concentrated solid solutions the Mott limit with $\mathrm{C}^{2 / 3}$ dependence is valid. For interstitial elements in BCC metals (with limited solubility), $\mathrm{C}^{1 / 2}$ dependence has been demonstrated. Conrad (1975), reported for interstitial solutes $C$, $\mathrm{N}$ and $\mathrm{O}$ in titanium equally good fit for both $\mathrm{C}^{1 / 2}$ and $\mathrm{C}^{2 / 3}$ plots. On the other hand, Mannan and Rodriguez (1973) reported better fit for $\mathrm{C}^{2 / 3}$ law for interstitial solution hardening in zirconium.

\section{Polycrystal work hardening}

Work hardening is a theme that has always fascinated the scientists investigating plastic deformation of metals. In the wake of the dislocation theory, there were intense efforts which led to the explanation of the three stages of single crystal work hardening in terms of primary slip (stage I), multiple slip (stage II) and cross slip (stage III). In fact what McLean said in 1967 continues to be true even today. 'A large part of the debate about flow stress and strain hardening is still preoccupied with single crystals. Yet far more metal is strained in polycrystalline form than in single crystal form and the polycrystal form therefore deserves study. Therefore in this discussion we shall focus attention on polycrystal work hardening. Another reason for doing this is that this is an area where I have made some research contributions.

The relationship between the strength $\sigma$ and square root of the dislocation density $\rho$

$$
\sigma=\sigma_{0}+M \beta \mu b \rho^{1 / 2}
$$

where $M$ is the Taylor factor relating shear stress $\tau$ with normal stress $\sigma_{0}$ in polycrystals $(\sigma=M \tau), \beta$ is a measure of the strengthening efficiency of dislocations and $\mu$ the shear modulus is well known. The equation is unique in that all the models for work hardening from the earlier theories associating work hardening with (i) pile-ups, (ii) tangles, (iii) jogs and (iv) forest dislocations to the more recent models involving concepts of continuously decreasing mobile dislocation free path and of statistical theories all predict that the strength will be proportional to the square root of the dislocation density. The equation is also supported by almost all experimental results.

Figure 3 shows the plots between the flow stress and the square root of dislocation density for polycrystalline zirconium and titanium (Rodriguez 1976). Both $\sigma_{0}$ and the slope $\mu \beta$ are found to decrease with temperature for both $\mathrm{Zr}$ and Ti. From the slopes of these lines $\mu \beta$ were evaluated using $\mu=C_{66}$, the shear modulus with the highest 

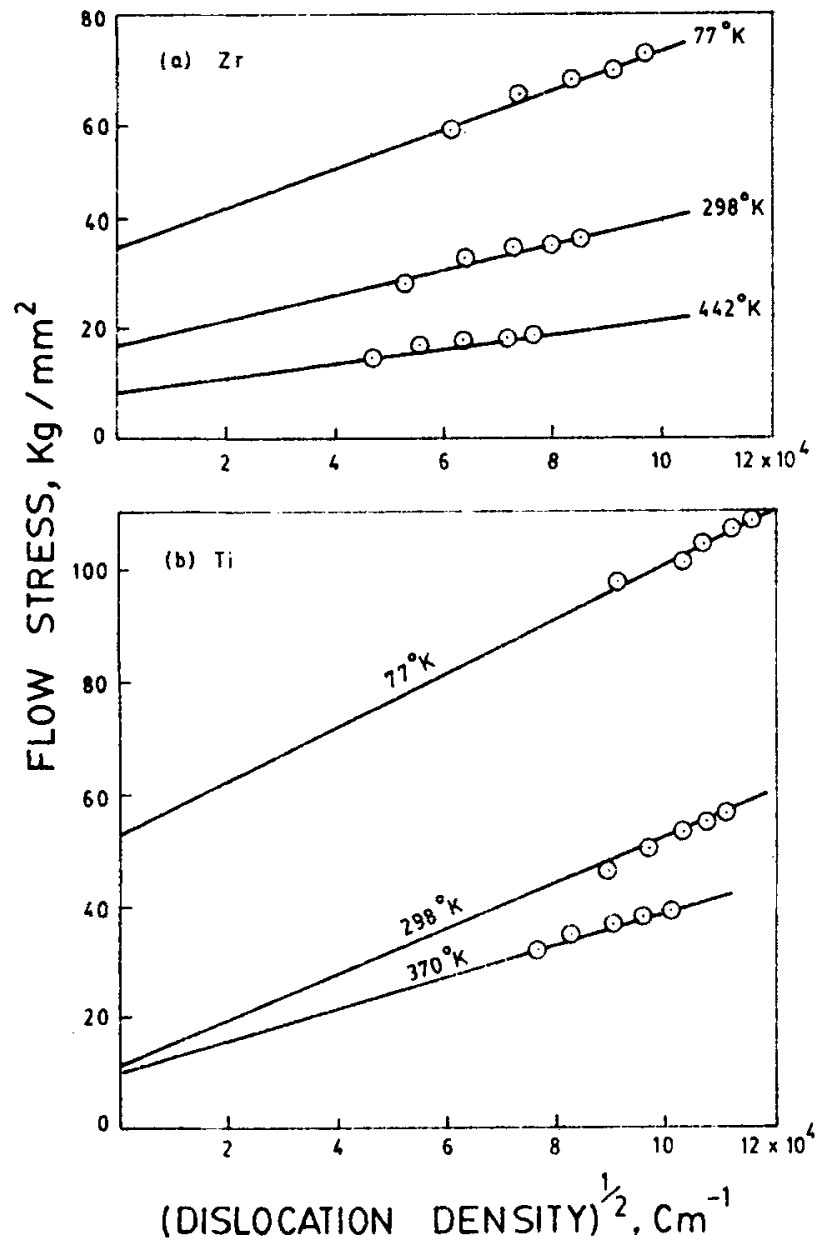

Figure 3. Plots of flow stress against square root of dislocation density at different temperatures: (a) $\mathrm{Zr}$ and (b) Ti (Rodriguez 1976).

Table 5. Values of $M \beta$ for $\mathrm{Zr}$ and $\mathrm{Ti}$.

\begin{tabular}{rcc}
\hline & \multicolumn{2}{c}{$M \beta$} \\
\cline { 2 - 3 } Temp. $\left({ }^{\circ} \mathrm{K}\right)$ & Zirconium & Titanium \\
\hline 77 & 2.6 & 3.6 \\
298 & 2.1 & 2.8 \\
370 & $\ldots$ & 1.8 \\
443 & 1.4 & $\cdots$
\end{tabular}

( $M=$ Taylor factor, $\beta=$ strengthening efficiency of dislocation; $\mu$ assumed to be $\mathrm{C}_{66}$ )

temperature dependence, and the results are shown in table 5. Values of $M \beta$ rather than $\beta$ are presented in table 5 as there is uncertainty on the value of $M$ for HCP metals. The lowest value possible for $M$ in 2 , while values as high as 6.5 have been suggested or indicated by results. The results of figures $1-3$ and table 5 have been explained on the 
basis of the distribution and arrangement of dislocations seen in the transmission electron microscopy (TEM) pictures (Ramani and Rodriguez 1972; Ramani et al 1973; Rodriguez 1976).

Before leaving this section on the strength of materials, I feel nccessary to say a few words on dislocation dynamics, which was very vigorously pursued both theoretically and experimentally in the sixties and seventies. The major interest has been in understanding the dependence of flow stress on temperature and strain rate. From the Orowan equation $\dot{\varepsilon}=\rho_{\mathrm{m}} b \bar{V}$, and therefore the subject essentially deals with the variation of $\rho_{\mathrm{m}}$ the mobile dislocation density and $V$ the average velocity of dislocations with stress and temperature. With the general assumption that $\rho_{n}$ does not vary with temperature and stress, there have been two approaches to model the variation of $\varepsilon$ with $\delta$ and $T$; the power law approach $\left[V \propto \sigma^{\mathrm{m}}\right]$ and the thermal activation strain rate analysis approach. In the latter approach, which postulates a stress dependent activation energy, the main interest has been in identifying the rate controlling dislocation mechanism. This is an area where my groups, both at and IGCAR, have been quite active and I have reviewed the progress in our understanding of the subject periodically on a number of occasions and would refer the readers to these reviews for more details (Dasgupta and Rodriguez 1972: Rodriguez 1979: Ray and Rodriguez 1988).

\section{Dislocations and crystal growth}

It was known that for crystal growth from either the vapour or a saturated solution, the rate of growth depends, among other things, on the degree of supersaturation (excess vapour or solute). For high values of supersaturation ( $\gg 50 \%$ for vapour growth), the crystal growth rate is admirabiy explained by the nucleation and growth mechanism. For crystals grown under very low supersaturation $(<.1 \%)$ the conventional nucleation theory predicts a rate which is $e^{-3000}$ times smaller than the observed values! (Kittel states that this is a record for largest difference between theory and observation).

Frank (1949) resolved the paradox in the crystal growth by using the screw dislocation mechanism. The major turning point in the theory of crystal growth was constituted by the paper by Burton et al - - the BCF screw dislocation model (Burton et al 1951). According to BCF model, if a screw dislocation emerges on the surface of a crystal, it provides a step on the surface. the edges of which provide the site for further growth of the crystal in much the same way as the edges of the two dimensional nucleus. This edge provided by the screw dislocation is self-perpetuating and after the crystal has thickened by $1,2 \ldots n$ number of layers, the ledge still remains. Thus in contrast to the molecularly flat surface of a crystal, which results when a crystal has grown by a two dimensional nucleus mechanism. the crystal which has grown by a dislocation mechanism will not be flat. It should have a spirally stepped pyramidal hill centred on the dislocation. Further, the step height of these spirals should be equal to be multiples of the unit cell size. Can such clear predictions be directly verified?

At that time (1950), A R Verma was in the Royal Holloway College. UK working for his doctorate degree in Tolanski's laboratory. By using ingeneously, the technique of phase contrast microscopy, Verma provided the evidence for the growth spirals in silicon carbide originating from a screw dislocation. His discovery was published as a leading note in Nature (Verma 1951). Simultaneously Amelinckx (1951) from Belgium also published the observation of growth spirals on silicon carbide crystals. In fact, 
both the papers appear on the same page in Vol. 167 of Nature! The first book on crystal growth and dislocations was published by Verma (1953) followed by a more exhaustive review by Amelinckx (1964). After his return to India, a combined study of interferometric and X-ray diffraction techniques on the same sample, and looking for their correlation, became the focal theme and culminated in the well-known book 'Polymorphism and Polytypism in Crystals' by Verma and Krishna (1966).

Let us now shift the emphasis to the question: how do the dislocations originate during the crystal growth? It may be recalled that in the fifties, the semiconductor transistor had revolutionized electronics and the single crystal was catapulted into the technology orbit from its limited role in the laboratory. The task of controlling dislocations during crystal growth, especially of semiconducting substrates became a high priority commercial venture. Considering the melt growth of crystals, three mechanisms of dislocation formation could be clearly identified. They are:

- Condensation of excess point defects present near the growth temperature to form prismatic dislocation loops.

- Non-uniform heat flow during solidification and ensuing thermal stress, causing plastic deformation.

- Defective seed crystal, accidental introduction of macroscopic foreign particles during growth, causing generation and multiplication of dislocations.

\section{Dislocations and device performance}

Native defects and dislocations profoundly influence the performance of semiconductor devices. A dislocation acts as a recombination centre for carriers, thereby contributing to non-radiative transitions and reducing the light-emitting efficiency.

The III-V compounds, because of their importance in device applications, have been subjected to several painstaking studies. It emerged that two important entities are responsible for degradation of devices based on III-V compounds. They are: dark-line defects (DLDs) and dark-spot defects (DSDs). The DLDs have been identified by TEM as three-dimensional dislocation networks consisting of long dislocation dipoles and small dislocation loops. The DLDs originate from precursor defects in the active semiconductor layer that are classified as DSDs since they appear as dark regions in luminescent images from the active layers. These defects act as electron-hole recombination centres and the non-radiative latent heat produced whenever a recombination occurs enhances the rates of diffusion, dissociation and annihilation giving rise in turn to the growth of DLDs and to device degradation.

TEM results on rapidly failed devices showed the defect structure corresponding to certain DLDs, consisting of dislocation dipoles, helical dislocations and dislocation loops to be responsible. It was almost definitely ascribed to be caused by poor quality substrates used for making the device. This is not a serious limitation as low dislocation density substrates are now available. The gradual failure, however, occurs even with high quality substrates and manifests as a progressively larger drive current for laser operation or as a continuous drop in the light output in light emitting diodes. The defect structures observed are: precipitates, multiple dislocations and extrinsic dislocation loops. The mechanism of the formation of such defect structures is believed to be due to the formation of point defects at epilayer-substrate interface and the subsequent growth in the active layer due to recombination assisted diffusion. 
I will close this topic by mentioning the recent work done to examine the influence of dislocations on the performance of GaAs field effect transistor. The following sequence of carefully designed experiments on 'FET microscopy' was performed by Miazawa and Nanishi (1983). About 1000 gates, $200 \mathrm{~mm}$ apart with the gate length to width equal to $1 \mathrm{~mm}$ by $6 \mathrm{~mm}$ were written on a standard GaAs wafer and the threshold voltage was measured for each microFET. Subsequently the wafer was etched in molten $\mathrm{KOH}$ to determine the overall dislocation density. The distance between each microgate and the nearest etch pit was also carefully measured. An interesting feature was discovered. The threshold voltage showed a large effect, varying from $-1 \mathrm{~V}$ to $+3 \mathrm{~V}$ as the distance increased to $20-30 \mathrm{~mm}$, while the acceptable global standard deviation for a FET is $\sim 100 \mathrm{mV}$. Understandably, there was a worldwide concern with regard to the Japanese results, since the prospects for large scale integration of GaAs FETs using high dislocation density (and cheaper) substrates would be discouraging. The present situation seems to be that for dislocation densities less than $3000 \mathrm{~cm}^{-2}$, the FET threshold voltage is independent of dislocation density. For higher values, there is a proximity effect, arising out of a dislocation lineage intersecting a FET at a low angle. There is also an evidence that the dislocations affect the impurity atmosphere (Swaminathan and Jordan 1993).

\section{Future directions}

I have so far highlighted the major topics in whatever has so far happened in dislocations. It will perhaps be appropriate to end the account by speculating on the possible future course(s) of development.

While discussing future directions, it is appropriate to recall that in the past dislocation theory has helped to solve old problems and also opened new fields of research to include materials more complex than the simple alloys of classical metallurgy or physical properties other than plasticity. One of the major problems, which is still not fully solved, is that of bridging the gap between the properties of individual dislocations and the behaviour of dislocations 'en masse' as observed in highly deformed materials.

A topic of much importance and relevance to us working in the technology of nuclear reactors is radiation damage resulting in irradiation swelling and irradiation growth in nuclear materials. Great efforts have been made to understand the nucleation and the development of dislocations networks and/or voids by the elimination of Frenkel defects produced under heavy radiation doses. In such conditions of large supersaturation of vacancies, the use of concepts near equilibrium do not hold and kinetic descriptions are necessary to tackle the problems of dislocation loops and the choice of atomic planes for the loops in anisotropic materials. The entire field still needs very basic and fundamental experiments to decide between the various possible interpretations [The experimental difficulties are formidable!] (for a recent review see, Rodriguez et al 1984).

The rheology of the earth's lower crust is determined by the plastic properties of the constituent materials, quartz and feldspar being the two main ones. Now, creep in many crystalline materials, changes as the applied stress decreases, from a power law creep with a stress exponent $n$ of 3 to 5 to Newtonian viscous flow with $n=1$. A Newtonian dislocation creep, involving the dislocation activation within the grain, is 
called Harper-Dorn (H-D) creep. The most recent observation by Wang et al (1994) of the H-D creep in quartzites indicates the lower crust of the earth flows like a Newtonian viscous fluid by a dislocation mechanism. The implication of such a finding is that if the H-D creep is assumed to be the rate controlling mechanism, then for the geological strain rate of the lower crust $\left[10^{-12} \mathrm{~s}^{-1}\right.$ at $\left.773 \mathrm{~K}\right]$, the calculated stress level in the lower crust is two orders lower than what was believed to be prevailing until now on the basis of the power law creep. This example illustrates the growing applications of dislocation science to even problems in geophysics.

The field of liquid crystals has seen an explosive growth in the last two decades. It was long back known (1920s) that the line singularities are equivalent to Volterra's rotation dislocations. They are therefore regarded as the earliest examples of dislocations observed in nature. What made this possible was the low viscosity of a liquid crystal, which allows them a fast recovery with low density of dislocations. This along with a strong coupling to light waves renders them easily observable in an ordinary microscope. The dislocation science gained fruitfully from the notion of line singularities in ordered structure without lattice. Extension of the ideas used in liquid crystals is now being made to magnetism, superfluidity and superconductivity. Yet another exciting direction is the extension of the concept of defects to quasicrystals and amorphous solids (Venkataraman et al 1989).

The crystalline phase of rare gases offers a testing ground for quantum phenomena. Studies performed on single crystals of $\mathrm{He}^{4}$ [prepared under pressure] showed that plasticity in this phase is through a classical and hysteretic motion of dislocations. There is as such no evidence for any fast quantum tunnelling process either for vacancies or for dislocations. Nevertheless, more experiments on these materials will be welcome.

In his closing address to the conference on 'Dislocations and Properties of Real Materials', conducted by the Institute of Metals, London, in 1984, Sir Alan Cottrell (Cottrell 1985) asked, 'Where is the "transistor" of dislocation theory? It is a disappointment that the concept of dislocations has not produced a spectacular and obvious technological advance comparable with the "transistor". He elaborated and suggested that there is perhaps one! To quote him again, 'Surely the one practical result, above all, that we expect from dislocation theory is the achievement in real materials of ideal strength. This has happened, of course, but by the drastically simple method of eliminating mobile dislocations altogether, either by using glassy structure or a material such as silicon nitride in which dislocations are naturally sessile. Having delivered its great, simple message, the theory of dislocations has departed from the scene and left the theory of fracture to cope with the problem converting the principle into practical materials, which of course has led on to the development of strong fibre composites. Carbon fibre is thus the "transistor" of dislocation theory.

Whether 'the carbon fibre can be regarded as the "transistor" of dislocation theory?' is a question that can be debated. But the carbon fibre leads us to the topic of composite materials, which according to Kelly (1989) 'are combinations of materials, used both in the intrinsic mode or extrinsic mode'. For instance, to produce a semiconductor laser, one has to combine a conductor, a specific insulator with prescribed band gap and dielectric constant and a semiconductor again with a specified band gap, mobility of carriers and their type. The composite marries these and produces a very specific device. Of course, it takes extreme cleverness to do this.

It is therefore appropriate to close my talk with the role of dislocations in influencing the properties of engineering composites, which along with new ceramics, new plastics 
and new alloys will dominate the twenty-first century. In engineering composites the ductility of the matrix is combined with the strength of the reinforcing phase. It is my belief that while the mechanics of load transfer from matrix to fibre particle is fairly well understood, there is much more we have to learn about what happens at the interface at the microscopic level. In this latter aspect, dislocations are important - for example, the evidence that dislocation density in the matrix is the maximum at the interface and decreases with distance from the interface is very recent (Chawla 1987). Both in the processing of composites and in their service behaviour under thermal and mechanical stresses, the role of matrix dislocations including at the interface, needs to receive more attention, particularly with reference to flaws like delamination.

\section{Acknowledgements}

It is a pleasure to acknowledge the collaboration of Dr K Govinda Rajan, Materials Science Division, Indira Gandhi Centre for Atomic Research (IGCAR), Kalpakkam in preparing this lecture. The help received from the Library and Information Service, IGCAR is also greatly acknowledged.

\section{References}

Amelinckx S 1951 Nature $\mathbf{1 6 7 9 3 9}$

Amelinckx S 1964 The direct obsertation of dislocations, Solid State Physics Supp 6 (New York: Academic Press)

Andrade E N and Da C 1937 J. Inst. Metals 60472

Ansell G S and Lenel F V 1960 Acta Metall. 8612

Biliby B A 1950 J. Inst. Metals 76613

Bhanu Sankara Rao K. Seetharaman V, Mannan S L and Rodriguez P 1983 Mater. Sci. Engg. 5893

Bollmann W 1956 Phys. Rev 1031588

Bragg W L and Nye J F 1947 Proc. R. Soc. A19 474

Burgers J M 1939 Proc. Kon. Ned. Akad. Wet. 42 293, 378

Burgers W G 1956 Ned Tigdschr. Natuurk 22245

Burton W K. Cabrera N and Frank F C 1951 Philos. Trans. Roy. Soc. (London) A243 299

Cahn R W 1949 J. Inst. Metals 79121

Chawla K K 1987 Composite materials - science and enyineering (New York: Springer-Verlag)

Conrad H 1975 in Physics of solid solution strengthening (eds.) E W Collings and H L Gegel (New York: Plenum Press! pp. 1-43

Cottrell A H 1953 Dislocation and plastic How in (rystals (Oxford: Clarendon Press)

Cottrell A H 1985 Dislocations and properties of real materials (London: Institute of Metals) p. 380

Dash W C 1956 J. Appl. Phys. 271193

Dasgupta P and Rodriguez P 1972 in Recent decelopments in metallurgical science and technology (New Delhi: Indian Institute of Metals Silver Jubilee Symposium) p. 47

Elam C-F 1936 Distortion of crystals (Oxford)

Fleischer R L 1961 Acta Metall. 9996

Frank F C and Read W T 1950 Phys. Rev. 79722

Friedel J 1956 Les dislocations (Paris: Gauthier-Villars)

Gilman J J and Johnston W G 1959 J. Appl. Phys. 30129

Herring C and Galt J K 1952 Phys. Ret. 851060

Hirsch P B. Horne R W and Whelan M J 1956 Philos. Mag. 1677

Hirth J P and Lothe J 1968 The'ory of dislocations (New York: McGraw Hill)

Howie A and Whelan M J 1962 Proc. R. Soc. A267 206

Jordan A S, Von Neida A R and Caruso R 1984 J. Crvst. Growth 70555 
Kelly A 1989 The techno-economics of new materials, in Materials in modern society (Denmark: Riso National Laboratory) p. 23

Mannan S L and Rodriguez P 1973 Trans. Indian Inst. Metals 2649

McLean D 1967 Canadian J. Phys. 45973

Miazawa S and Nanishi Y 1983 Jpn J. Appl. Phys. 22 Suppl. 22-1, 419

Mott N F and Nabarro F R N 1948 Report on strength of solids (London: Physical Society) p. 1

Nabarro F R N 1947 Proc. Phys. Soc. 59256

Nabarro F R N 1967 Theory of crystals dislocations (Oxford: Clarendon Press)

Nabarro F R N (ed) 1979--1989 Dislocations in solids (Amsterdam: North Holland Pub. Co.) Vol. 1-Vol. 8

Orowan E 1934 Z. Phys. 605, 614, 634

Orowan E 1940 Proc. Phys. Soc. 528

Orowan E 1947 Symposium on international stresses (London: Inst. of Metals) p. 451

Peach M and Koehler J S 1950 Phys. Rev. 80436

Peierls R 1940 Proc. Phys. Soc. 5234

Petroff P M. Logan R A and Savage A 1980 Phys. Rev. Lett. 44289

Polanyi M 1934 Z. Phys. 605, 614,634

Ramani S V and Rodriguez P 1970 Scr. Metall. 4

Ramani S V and Rodriguez P 1972 Canadian Met. Q. 1161

Ramani S V, Mukhopadhyay P, Rodriguez P and Krishnan R 1973 Indian J. Tech. 11346

Ray S K and Rodriguez P 1988 Bull. Mater. Sci. 10133

Read W T 1953 Dislocations in crystals (New York: McGraw Hill)

Rodriguez $\mathbf{P}$ and Asundi M 1970 J. Mater. Sci. 5218

Rodriguez P 1976 Low temperature deformation in hard HCP metals, Ph.D. Thesis, Indian Institute of Science, Bangalore

Rodriguez P 1979 in Metal Sciences, the emerging frontiers (ICMS-77) (eds) T R Anantharaman, S L Malhotra. S Ranganathan and P Rama Rao (Calcutta: Indian Institute of Metals) pp. 245-257

Rodriguez P, Krishnan R and Sundaram C V 1984 Bull. Mater. Sci. 6339

Rodriguez $\mathrm{P} 1994$ Strength of metals and alloys - A historical perspective in International Conference on fifty years of evolution of metallurgy), (Calcutta: Bengal Engg. College) pp 105-132(This contains a bibliography of 135 references)

Schmid E and Boas W 1936 Kristallplastizitat (Berlin: Springer Verlag) (This book has an extended bibliography that covers the work cited in Section 2), 1950 Plasticity of crystals English Translation, (London: FA Hughes)

Shockley W and Read W T 1949 Phys. Rev. 75692

Shockley W and Read W T 1950 Phys. Rev. 78275

Suo Z 1994 Acta Metall. Mater. 423581

Swaminathan V and Jordan A S 1993 in Imperfections in III-V materials, (ed.) E R Weber (New York: Academic Press) Ch. 7, Vol. 38

Taylor G I 1934 Proc. R. Soc. 145362

Van Bueren H G 1960 Imperfections in crystals (Amsterdam: North Holland)

Venkataraman G, Sahoo D and Balakrishnan V 1989 Beyond the crystalline state (Berlin: Springer-Verlag) Verma A R 1951 Nature 167939

Verma A R 1953 Dislocations and crystal growth (London: Butterworths) Supp 6 (New York: Academic Press)

Verma A R and Krishna P 1966 Polymorphism and polytypism in crystals (New York: John Wiley)

Wang J N, Hobbs B E. Ord A, Shimamoto T and Toriumi M 1994 Science 2651204 